\title{
Increased risk of heart valve regurgitation after mediastinal radiation for Hodgkin's disease: an echocardiographic study
}

M B Lund, H Ihlen, B M R Voss, A F Abrahamsen, O Nome, J Kongerud, M Stugaard, K Forfang

\begin{abstract}
Objective-To assess by echocardiography the occurrence and degree of late cardiac sequelae after treatment for Hodgkin's disease by radiation and chemotherapy.

Patients and methods-In Norway from 1980 to 1988,129 patients $<50$ years old with Hodgkin's disease had curative treatment with mediastinal radiation, with or without chemotherapy. $116(90 \%)$ of these patients (mean (SD) age 37 (7) years, 67 males) were examined by echocardiography 5-13 years after treatment. 40 healthy individuals (mean (SD) age 40 (11), 20 males) were examined as controls. All those examined were in regular sinus rhythm.
\end{abstract}

Results-Grade > 1 (scale 0-3) aortic and/or mitral valvar regurgitation was found in $24 \%$ of the patients (15\% aortic, $7 \%$ mitral, and $2 \%$ aortic + mitral), affecting $46 \%$ of the females $v 16 \%$ of the males $(\mathbf{P}<0.001)$. Female gender was a significant risk factor for aortic and mitral regurgitation (odds ratio $4 \cdot 7$, $95 \%$ confidence interval $2 \cdot 0$ to $11 \cdot 2$ ), whereas age, period of follow up, radiation dose, and chemotherapy were not. Thickened pericardium was diagnosed in $15 \%$ of the patients. No risk factors were identified. No cases of pericardial thickening or valvar regurgitation grade $>1$ were recorded in the control group. Mean values for measured and calculated indices of systolic and diastolic function were within the normal range for patients and controls. The patients had reduced $E / A$ ratio compared with the healthy controls (E/A $1 \cdot 1 v 2 \cdot 0, P<0 \cdot 001)$.

edical Department B, Cardiology Section and Department of Thoracic Medicine, The National Hospital, University of Oslo, Norway

$M$ B Lund

$M$ B Lund

$H$ Ihlen

B M R Voss

J Kongerud

M Stugaard

K Forfang

The Norwegian

Radium Hospital,

Oslo, Norway

A F Abrahamson

O Nome

Correspondence to:

Dr M B Lund, Department of Thoracic Medicine, The National Hospital, University of Oslo, N-0027 Oslo, Norway.

Accepted for publication 6 February 1996
Conclusions-Abnormal left sided valvar regurgitation was detected in one fourth of the patients, affecting the aortic valve in more than half of the cases. Females had an increased risk of valvar regurgitation. Echocardiographic screening after high-dose mediastinal radiation is recommended.

\section{(Heart 1996;76:591-595)}

Keywords: echocardiography, valvar regurgitation, radiation, Hodgkin's disease.

Hodgkin's disease provides a clinical model for studying long-term effects of cancer treatment. Mainly young adults are affected, and more than $70 \%$ are cured ${ }^{1}$ by radiotherapy alone or combined with chemotherapy. Both treatments are potentially cardiotoxic. ${ }^{2}$

Radiation-induced cardiac injury includes pericarditis, coronary artery stenosis, myocardial fibrosis, and valvar dysfunction. ${ }^{3}$ One of the standard chemotherapy regimens used in Hodgkin's disease includes anthracyclines, agents known to induce cardiomyopathy that may progress to fatal heart failure. ${ }^{4}$ The toxicity of anthracyclines may be enhanced by multidrug combinations and additional radiation. ${ }^{5}$

In Norway, up until 1988, all patients with Hodgkin's disease were treated at one centre. The patients were recruited from the entire country, were referred and selected according to uniform criteria, and had standardised treatment procedures. Today this policy has provided us with a well defined national patient population available for long-term follow up.

Echocardiography has been used in only one large clinical study to evaluate the longterm toxicity of high-dose mediastinal radiation. ${ }^{6}$ In our national cohort of Hodgkin disease survivors, we aimed to assess the occurrence and degree of late cardiac sequelae after such treatment.

\section{Patients and methods}

PATIENTS

The study was based on all 427 consecutive patients who were treated for Hodgkin's disease at the Norwegian Radium Hospital during the period 1980-88. By 1 January 1993, 282 of these patients were still alive. The study was limited to patients who had been treated with standardised mediastinal radiation alone or in combination with chemotherapy. Only patients aged under 50 years at the time of diagnosis and who had been in complete remission for more than five years at the time of follow up were invited to participate. Of the 129 patients invited, 13 were lost to follow up. The remaining 116 patients $(90 \%)$ were enrolled in the study, after giving their signed informed consent. The study was approved by the Regional Ethics Committee.

Hodgkin's disease had been diagnosed on the basis of histopathological examination of a lymph-node biopsy specimen. Radiation only had been administered to 40 patients, while the remaining 76 high risk patients had received additional chemotherapy.

\section{RADIOTHERAPY}

Fractional doses of 1.8 or $2.0 \mathrm{~Gy}$ were given five days a week to a mean (SD) total dose of 
$40.6(1.4)$ Gy. An anterior or posterior field was treated sequentially every other day. A selection of standard blocks was adapted to optimise lung shielding. No subcarinal blocks or systematic cardiac shields were used in the mediastinal part of the field. The treatment technique has been described in detail elsewhere. ${ }^{78}$

\section{CHEMOTHERAPY}

Regimens containing anthracyclines

Four to eight courses of alternating ABVD (doxorubicin, bleomycin, vincristine, and dacarbazine) and LVPP (chlorambucil, vinblastine, procarbazine, and prednisolone) had been given to 38 patients, and four courses of ABVD or EBVP (epirubicin, bleomycin, vinblastine, and prednisone) to eight patients. Doxorubicin and epirubicin had been given in doses of $25 \mathrm{mg} / \mathrm{m}^{2}$ and $40 \mathrm{mg} / \mathrm{m}^{2}$ respectively. The median cumulative doses were: doxorubicin 290 (range 140-400) $\mathrm{mg}$ and epirubicin 373 (range $320-400$ ) $\mathrm{mg}$.

\section{Other regimens}

Four to eight courses of LVPP or MVPP (mustine, vinblastine, procarbazine, and prednisone) had been given to 30 patients.

\section{CLINICAL ASSESSMENT}

Assessment at follow up included a structured clinical interview and physical examination. special attention was paid to symptoms and signs of cardiovascular disease. Use of medication before and after Hodgkin's disease treatment were recorded. The patients were categorised according to the New York Heart Association (NYHA) classification. Previous medical records were reviewed for the occurrence of cardiac disease (including cardiac murmur and rheumatic fever) before Hodgkin's disease treatment.

Table 1 Criteria for semiquantitative grading of chronic valvar regurgitation by echocardiography

\begin{tabular}{|c|c|c|c|c|}
\hline & $\begin{array}{l}\text { Grade } \\
0-1\end{array}$ & 1 & 2 & 3 \\
\hline $\begin{array}{l}\text { Aortic regurgitation: } \\
\text { Jet/outflow tract diameter (\%) } \\
\text { Pandiastolic } \\
\text { Signal intensity } \\
\text { Regurgitant volume† } \\
\text { Jet pressure half time }(\mathrm{ms}) \dagger \\
\text { End diastolic reversed } \\
\text { flow in DA }(\mathrm{m} / \mathrm{s}) \dagger\end{array}$ & $\begin{array}{l}<20 \\
\text { No } \\
\text { Weak }\end{array}$ & $\begin{array}{l}20-30 \\
\text { Weak }\end{array}$ & $30-50$ & $\begin{array}{l}>50 \\
\text { Yes } \\
<350 \\
>0 \cdot 25\end{array}$ \\
\hline $\begin{array}{l}\text { Mitral regurgitation: } \\
\text { Jet/atrial area }(\%) \\
\text { Left atrial diameter }(\mathrm{cm}) \\
\text { Holosystolic } \\
\text { Signal intensity } \\
\text { Regurgitant volume } \\
\text { Systolic reversal of PV flow† } \\
\text { Proximal flow acceleration }(\mathrm{m} / \mathrm{s}) \dagger\end{array}$ & $\begin{array}{l}<10 \\
<4 \\
\text { No } \\
\text { Weak }\end{array}$ & $\begin{array}{l}10-20 \\
<4 \\
\text { Weak }\end{array}$ & $\begin{array}{l}20-40 \\
4-5\end{array}$ & $\begin{array}{l}\text { Yes } \\
\text { Yes } \\
>0 \cdot 6\end{array}$ \\
\hline $\begin{array}{l}\text { Tricuspid regurgitation: } \\
\text { Jet/atrial area (\%) } \\
\text { Left atrial diameter (cm) } \\
\text { Holosystolic } \\
\text { Signal intensity } \\
\text { Regurgitant volume† } \\
\text { Systolic reversal of SCV flow† }\end{array}$ & $\begin{array}{l}<10 \\
<4 \\
\text { No } \\
\text { Weak }\end{array}$ & $\begin{array}{l}<10 \\
<4 \\
\text { Weak }\end{array}$ & $\begin{array}{l}10-30 \\
4-5\end{array}$ & $\begin{array}{l}>30 \\
>5 \\
\text { Yes } \\
\text { Yes }\end{array}$ \\
\hline $\begin{array}{l}\text { Pulmonary regurgitation: } \\
\text { Jet length }(\mathrm{cm}) \\
\text { Pandiastolic } \\
\text { Signal intensity } \\
\text { Regurgitant volume† }\end{array}$ & $\begin{array}{l}<1 \\
\text { No } \\
\text { Weak }\end{array}$ & $\begin{array}{l}1-2 \\
\text { Weak }\end{array}$ & $>2$ & $\begin{array}{l}>2 \\
\text { Yes }\end{array}$ \\
\hline
\end{tabular}

$\star$ Denotes criteria for grade $0-1$ and 1 ; †Denotes criteria for grade 3 .

DA, descending aorta; SCV, superior caval vein; proximal flow acceleration, systolic intraventricular retrograde acceleration towards the mitral valve; $\mathrm{PV}$, pulmonary vein.
REFERENCE GROUP

Forty healthy subjects (20 males and 20 females, mean (SD) age 40 (11) years) were recruited as a reference group. There were about 10 individuals in each decade between 20 and 60 years. None had a history of cardiovascular disease or hypertension and no medication was being taken. Physical examination was normal in all. Echocardiography included Doppler examination of the aortic, mitral, and tricuspid valves.

\section{ECHOCARDIOGRAPHY}

We used a Vingmed CFM 700 or 750 ultrasound device (Vingmed Sound, Horten, Norway) with a duplex mechanical annular array probe $(3.25 \mathrm{mhz}$ for imaging tissue and $2.5 \mathrm{mhz}$ for Doppler recordings). The subjects were examined in the lateral recumbent position after 15 minutes of rest. The heart was visualised by standard ultrasonic techniques and acoustic windows. Dimensions were determined by $\mathrm{M}$ mode echocardiography or a cross sectional technique when appropriate. Pulsed, continuous, and colour Doppler echocardiography in at least three planes was used to assess valvar function.

Table 1 shows the criteria for quantifying valvar regurgitation. ${ }^{910}$ The ratio between the diameters of the regurgitant jet and the outflow tract was used as main quantitative criterion for the grading of aortic regurgitation. Main criteria for the grading of mitral and tricuspid regurgitation were the ratios between the areas of the respective jets and the atrial areas. The jet length was the main criterion for grading pulmonary regurgitation. The other variables (table 1) were used as supporting criteria. Regurgitation satisfying the echocardiographic jet size criteria of grade 1 were defined as grade 1-2 when the continuous Doppler signal from the jet was more than weak-that is, spectral analysis showed a distinct continuous signal about half the intensity of anterograde flow. Two supporting criteria were required for classification as grade 3 aortic, mitral, and tricuspid regurgitation and one was needed for grade 3 pulmonary regurgitation. Valvar regurgitation $>$ grade 1 was defined as abnormal.

Abnormal pericardium was diagnosed as described by Feigenbaum. ${ }^{11}$ Cardiac output was measured at the level of the aortic annulus as previously described. ${ }^{12}$ Normal values for cardiac dimensions and blood flow were defined according to a reference material of healthy Norwegian adults. ${ }^{13} 14$

STATISTICAL ANALYSIS

Calculations were performed with the SPSS/PC statistical computing package. Categorical data were compared by the $\chi^{2}$ test and group means by a two-tailed unpaired Student's $t$ test or one way analysis of variance. For multiple comparisons the correction methods of Bonferroni or Scheffe were applied. Multiple linear regression was used to detect relations between continuous echocardiographic variables and relevant independent covariates. Associations between outcome 
variables (valvar regurgitation and pericardial thickening) and determinants of interest (gender, age, observation period, radiation dose, and chemotherapy) were estimated by multiple logistic regression analyses.

\section{Results}

CLINICAL FINDINGS

The patients' clinical characteristics are outlined in table 2. No patient had diagnosed cardiovascular disease, cardiac murmur, or rheumatic fever before treatment for Hodgkin's disease, and none had used potentially cardiotoxic drugs other than those included in the Hodgkin regimens. After treatment for Hodgkin's disease four patients had had a myocardial infarction and one had required concomitant aortic valve replacement and coronary artery bypass grafting. Systolic murmurs (grade 1 or 2) were detected in 13 $(11 \%)$ of the patients. No diastolic murmurs were recorded. Dyspnoea on exertion was reported by $32(27 \%)$ of the patients, classified as NYHA II in $23 \%$ and NYHA III in $4 \%$. The patients and the controls were comparable with respect to blood pressure

Table 2 Clinical characteristics at inclusion of 116 longterm survivors of Hodgkin's disease

\begin{tabular}{ll}
\hline Characteristics & $\begin{array}{c}\text { Patients } \\
(n=116)\end{array}$ \\
\hline Male/female & $67 / 49$ \\
Age (mean (SD), yr) & $37(7)$ \\
Follow up (mean (SD), yr) & $9(3)$ \\
Diagnosed heart disease post-HD & 5 \\
Antihypertensive therapy & 2 \\
Thyroxine replacement & 18 \\
Cardiac murmurs & 13 \\
Dyspnoea on exertion & 32 \\
\hline HD, Hodgkin's disease. Unless & otherwise specified, values \\
= number of patients. &
\end{tabular}

Table 3 Echo-Doppler indices (mean (SD)) by gender in 116 long-term survivors of Hodgkin's disease and 40 healthy controls

\begin{tabular}{|c|c|c|c|c|}
\hline \multirow[b]{2}{*}{$\begin{array}{l}\text { Echo-Doppler } \\
\text { indices }\end{array}$} & \multicolumn{2}{|l|}{ Males } & \multicolumn{2}{|l|}{ Females } \\
\hline & $\begin{array}{l}\text { Patients } \\
(n=67)\end{array}$ & $\begin{array}{l}\text { Controls } \\
(n=20)\end{array}$ & $\begin{array}{l}\text { Patients } \\
(n=49)\end{array}$ & $\begin{array}{l}\text { Controls } \\
(n=20)\end{array}$ \\
\hline $\begin{array}{l}\text { LVEDD }(\mathrm{cm}) \\
\text { LVESD }(\mathrm{cm}) \\
\text { LV-SF }(\%) \\
\text { IVS }(\mathrm{cm}) \\
\text { LVPW }(\mathrm{cm}) \\
\text { LA }(\mathrm{cm}) \\
\text { E/A }\end{array}$ & $\begin{array}{l}5.04(0.54) \\
3.40(0 \cdot 39) \\
33(5) \\
0.99(0.19) \\
0.90(0 \cdot 15) \\
3.34(0 \cdot 60) \\
1.14(0.29)^{\star}\end{array}$ & $\begin{array}{l}5.35(0.64) \\
3.52(0.75) \\
34(7) \\
0.92(0.20) \\
0.87(0.24) \\
3.20(0.45) \\
1.86(0.54)\end{array}$ & $\begin{array}{l}4.67(0.44) \\
3.08(0.39) \\
34(7) \\
0.88(0.16) \\
0.77(0.13) \\
2.93(0.44) \\
1.15(0.31)^{\star}\end{array}$ & $\begin{array}{l}4.69(0.34) \\
3.13(0.30) \\
37(5) \\
0.83(0.17) \\
0.67(0.19) \\
2.95(0.48) \\
2.13(0.78)\end{array}$ \\
\hline
\end{tabular}

$\mathrm{P}<0.001 v$ controls.

E/A, peak early diastolic velocity/peak atrial velocity; IVS, interventricular septum; LA, left atrium; LVEDD, left ventricular end diastolic diameter; LVESD, left ventricular end systolic diameter; LVPW, left ventricular posterior wall; LV-SF, left ventricular shortening fraction.

Table 4 Echocardiographic evaluation of valve regurgitation in 116 long-term survivors of Hodgkin's disease and 40 healthy controls

\begin{tabular}{|c|c|c|c|c|c|c|c|}
\hline \multirow{2}{*}{$\begin{array}{l}\text { Regurg } \\
\text { grade } \\
(0-3)\end{array}$} & \multicolumn{2}{|l|}{ Aortic } & \multicolumn{2}{|l|}{ Mitral } & \multicolumn{2}{|l|}{ Tricuspid } & \multirow{2}{*}{$\begin{array}{l}\text { Pulmonary } \\
\text { Pts } \\
n(\%)\end{array}$} \\
\hline & $\begin{array}{l}\text { Pts } \\
n(\%)\end{array}$ & $\begin{array}{l}\text { Ctrs } \\
n(\%)\end{array}$ & $\begin{array}{l}\text { Prs } \\
n(\%)\end{array}$ & $\begin{array}{l}\text { Ctrs } \\
n(\%)\end{array}$ & $\begin{array}{l}\text { Pts } \\
n(\%)\end{array}$ & $\begin{array}{l}\text { Ctrs } \\
n(\%)\end{array}$ & \\
\hline $\begin{array}{l}0 \\
0-1 \\
1 \\
1-2 \\
2 \\
2-3 \\
3\end{array}$ & $\begin{aligned} & 76(66) \\
& 9(8) \\
& 11(9) \\
& 7(6) \\
& 12(10) \\
& 1(1) \\
& 0\end{aligned}$ & $\begin{array}{l}37(93) \\
3(7) \\
0 \\
0 \\
0 \\
0 \\
0\end{array}$ & $\begin{array}{l}64(55) \\
25(21) \\
15(13) \\
5(4) \\
6(5) \\
1(1) \\
0\end{array}$ & $\begin{array}{l}30(75) \\
9(23) \\
1(2) \\
0 \\
0 \\
0 \\
0\end{array}$ & $\begin{array}{l}39(33) \\
40(35) \\
31(27) \\
4(3) \\
2(2) \\
0 \\
0\end{array}$ & $\begin{array}{l}19(48) \\
16(40) \\
5(12) \\
0 \\
0 \\
0 \\
0\end{array}$ & $\begin{array}{l}59(50) \\
28(24) \\
7(23) \\
2(2) \\
0 \\
0 \\
0\end{array}$ \\
\hline
\end{tabular}

Ctrs, controls; Pts, patients.
$(120 / 80 \mathrm{mmHg} v 130 / 80 \mathrm{mmHg})$ and body surface area $\left(1.9 \mathrm{~m}^{2} v 1.8 \mathrm{~m}^{2}\right)$. Regular sinus rhythm was present in all subjects.

\section{ECHOCARDIOGRAPHY}

For both male and female patients the mean values for all measured and calculated echocardiographic indices were within the normal range (table 3), and differed significantly from the healthy controls only for the ratio between peak early $(\mathrm{E})$ and late $(\mathrm{A})$ diastolic transmitral flow velocities (E/A $1 \cdot 1 v 2 \cdot 0$, $P<0.001)$. The patients with coronary artery disease and hypertension were comparable with the rest of the patients with respect to $\mathrm{E} / \mathrm{A}$ ratio (E/A $1 \cdot 1 v 1.0)$. No significant differences in indices of systolic and diastolic function were seen between the two treatments, nor could we demonstrate a quantitative or qualitative effect of anthracylines.

Thickened pericardium was noted in 18 $(15 \%)$ of the patients. They all had normal atrial dimensions, shortening fraction of the left ventricle, and cardiac index. The $\mathrm{E} / \mathrm{A}$ ratio was below 0.8 in four, but the deceleration time of peak early velocity was normal in all. We found no association between pericardial thickening and sex, age, period of follow up, or treatment. No abnormality of the pericardium was detected in the controls.

Five patients had increased echoes from the aortic valve without showing a gradient. Three of them had no regurgitation, the fourth had dilatation of the aortic annulus and root with grade 2 regurgitation and the fifth had regurgitation grade $1-2$. In no other patients were structural abnormalities observed. Valvar thickening was not recorded in the control group.

Table 4 shows the occurrence and degree of valvar regurgitation in patients and controls.

In 36 patients (31\%), 40 valves with pathological (that is, grade $>1$ ) regurgitation were recorded at the aortic valve in 18 patients, at the mitral valve in eight, at both the aortic and mitral valve in two, at the tricuspid valve in four, at both the mitral and tricuspid in two, and at the pulmonary valve in two. Patients with aortic and mitral regurgitation grade $>1$ had higher left ventricular end diastolic diameters than the rest of the patients $(2.7 v 2.5$ $\left.\mathrm{cm} / \mathrm{m}^{2}, \mathrm{P}<0.001\right)$. Those with pathological mitral regurgitation also had increased left atrium diameter $\left(1.9 v 1.6 \mathrm{~cm} / \mathrm{m}^{2}, \mathrm{P}=0.01\right)$; but none had dimensions outside the normal limits.

Aortic and/or mitral regurgitation grade $>1$ was detected in all patients who had cardiac murmurs. No cases of valvar stenosis were recorded. We found no dose-response effect of radiation dose or fractionation on the occurrence of valvar regurgitation. Grade $>1$ regurgitation occurred in $49 \%$ of the female patients and in $18 \%$ of the males $(P<0.001)$. When we controlled for sex, age, follow up period, radiation dose, and chemotherapy in a logistic regression model, sex was the only significant predictor for grade $>1$ regurgitation (odds ratio $4 \cdot 7,95 \%$ confidence interval $2 \cdot 0$ to $11 \cdot 2)$. No subject in the reference group had 
regurgitation grade $>1$ (table 4$)$ and none had valvar stenosis.

\section{Discussion}

The major finding of this study was that abnormal aortic regurgitation (that is, grade $>1$ ) was diagnosed in $17 \%$ of the patients. Compared with our control group and with another reference material, ${ }^{15}$ both the proportion and severity of aortic regurgitation were outside the normal physiological range..$^{15} 16$

Our findings do not accord with the prevailing opinion that valvar dysfunction is a rare sequelae after mediastinal radiotherapy, ${ }^{3}$ an assumption based mainly on studies from the pre-Doppler era. ${ }^{17-19}$ Although previous noninvasive studies have reported little or no evidence of valvar dysfunction, the occurrence of severe valvar disease following radiation has been documented in case reports ${ }^{20}$ and in angiographic studies of selected patients. ${ }^{21}$

To our knowledge, Doppler ultrasound has been used in three earlier follow up studies of Hodgkin survivors. ${ }^{6223}$ Gustavsson et al ${ }^{22}$ found valve thickening and left-sided regurgitation in $40 \%$ of their patients. Doppler colour flow mapping was not used and only 25 patients were studied. Kreuser $e t a l^{23}$ reported a similar prevalence of valve thickening, but only one case of regurgitation. However, because their study was designed mainly to assess chemotherapy associated cardiotoxicity, only two thirds of the patients had been given radiation and the total dose had not exceeded $30 \mathrm{~Gy}$ for any patient. Glanzmann et $a l^{6}$ reported left-sided valve abnormalities in $32 \%$ of the patients, classified as sclerotic lesions in most. Regurgitation occurred in $16 \%$, but affected the aortic valve in only $6 \%$ of the cases. No valvar lesions were detected in patients who had received $30 \mathrm{~Gy}$ or less. This suggests a threshold dose of about $30 \mathrm{~Gy}$, which may explain the low prevalence of valvar dysfunction observed by Kreuser et al..$^{23}$

Left-sided regurgitation predominated in our patients. This result contrasts with what was found in healthy subjects, ${ }^{15} 16$ but accords with reports on radiation-induced valvar disease. ${ }^{20}$ Left-sided lesions accounted for $93 \%$ of the cases reported up until $1991,,^{20}$ and in a more recent angiographic series 12 of 15 patients with radiation-associated coronary artery disease had left-sided valvar lesions. ${ }^{24}$

The prevalence of Doppler detected regurgitation reported in different patient groups will depend on where the limit between normal and abnormal regurgitation has been set. Often this limit has not been clearly defined, which may explain the contrasting results. Because we also examined a control group, we believe our results indicate a real excess of leftsided valvar incompetence in the patient group. The increased left ventricular and atrial dimensions seen in the patients with left-sided regurgitation indicates that this finding was haemodynamically important.

Female patients were at increased risk of valvar regurgitaton. This difference between the sexes was not found in our reference group or in other prevalence studies of healthy subjects. ${ }^{1516}$ Studies of radiation-associated valvar disease seem to include a majority of women. ${ }^{2021} \mathrm{We}$ cannot explain why females in our study group should be more susceptible to valvar injury than males. They were comparable in terms of baseline clinical characteristics, they were treated with the same radiation technique, and they received the same dose to the heart.

Chemotherapy, with or without anthracyclines, did not increase the risk of valvar dysfunction. This suggests that radiation itself is the prime cause of valvar injury. Because the range of doses was narrow (40-42 Gy) we were unable to demonstrate a dose-response effect of radiation.

Pericardial thickening was recorded in $15 \%$ of our patients, in most cases there was no sign of haemodynamic impairment. Previous studies have reported a variable prevalence of pericardial pathology. ${ }^{6} 1819$ This inconsistency may partly be due to patient selection and partly to differences in radiation technique.

For the patients, as a group, the mean values for measured and calculated indices of systolic and diastolic function were within the normal range. However, compared with the healthy controls, the patients had a significantly reduced E/A ratio, implying that filling of the ventricle occurred later in the diastole. We found no significant differences in myocardial function between patients who had received additional chemotherapy and those treated with radiation only. This is probably because the median cumulative dose of anthracyclines had been kept well below the recommended threshold dose. ${ }^{4}$

We diagnosed left-sided valvar regurgitation in a high proportion of long-term survivors of Hodgkin's disease. Most noteworthy is the high prevalence of significant aortic regurgitation, and the increased risk of valvar lesions in female patients. We recommend echocardiographic screening after high-dose mediastinal radiation to identify patients with valvar patholgy and assess their need for endocarditis prophylaxis, treatment, or follow up.

1 Hoppe RT, Coleman CN, Cox RS, Rosenberg SA, Kaplan HS. The management of stage I-II Hodgkin's disease with The Stanford experience. Blood 1982;59:455-65.

2 Lancaster LD, Ewy GA. Cardiac consequences of malignancy and their treatment. Ann Intern Med 1984;30; 275-93.

3 Arsenian MA. Cardiovascular sequelae of thoracic radiaArsenian MA. Cardiovascular sequelae of the
tion. Prog Cardiovasc Dis 1991;33:299-311.

4 Kantrowitz NE, Bristow MR. Cardiotoxicity of antitumor agents. Prog Cardiovasc Dis 1984;27:195-200.

5 Minow RA, Benjamin RS, Lee ET, Gottlieb JA. Adriamycin cardiomyopathy-risk factors. Cancer 1977;39. 1397-1402.

6 Glanzmann C, Huguenin P, Lutolf UM, Maire R, Jenni R, Gumppenberg V. Cardiac lesions after mediastinal irradiation for Hodgkin's disease. Radiother Oncol 1994;30 43-54.

7 Jetne V. Treatment of Hodgkin's disease by radiation therapy. Acta Radiol 1972;313(S):67-75.

8 Abrahamsen AF, Hest H. Mantle field irradiation for stages IA and IIA Hodgkin's disease. Scand $\mathcal{F}$ Haemato 1981;26:306-10.

9 Feigenbaum H. Echocardiography. 5th ed. Philadelphia: Lea and Febiger, 1994;251-91.

10 Hatle L, Angelsen B. Doppler ultrasound in cardiology. 2nd ed. Philadelphia: Lea and Febiger, 1985;154-88.

11 Feigenbaum H. Echocardiography. 5th ed. Philadelphia: Lea and Febiger, 1994;586-88. 
12 Ihlen $\mathrm{H}$, Amlie JP, Dale J, Forfang K, Nitter-Hauge S, Otterstad JE, et al. Determination of cardiac output by Doppler echocardiography. Br Heart $f$ 1984;51:54-60.

13 Knutsen KM, Stugaard M, Michelsen S, Otterstad JE. Mmode echocardiographic findings in apparently healthy, 1989;225:111-5.

14 Knutsen KM, Otterstad JE, Frøland G, Stugaard M, Michelsen S. Determination of cardiac output by Doppler echocardiography in apparently healthy, nonathletic Norwegians aged 20-70 years. Am $\mathcal{f}$ Noninvas Cardiol 1989;3:36-41.

15 Jobic Y, Slama M, Tribouilloy C, Wah LLC, Choquet D, Boschat J, et al. Doppler echocardiographic evaluation of valve regurgitation in healthy volunteers. Br Heart $\mathfrak{f}$ valve regurgitation

16 Yoshida K, Yoshikawa J, Shakudo M, Akasaka T, Jyo Y, Takao S, et al. Color Doppler evaluation of valvular egurgitation in normal subjects. Circulation 1988;78: 840-7.

17 Gottdiener JS, Katin MJ, Borer JS, Bacharach SL, Green MV. Late cardiac effects of therapeutic mediastinal irradi-

18 Perrault DJ, Levy M, Herman JD, Burns RJ, Shlomo BZ,
Druck MN, et al. Echocardiographic abnormalities following cardiac radiation. $f$ Clin Oncol 1985;3:546-51.

19 Sintonen SP, Tøtterman KJ, Salmo M, Siltanen P. Late cardiac effects of mediastinal radiotherapy in patients with Hodgkins disease. Cancer 1987;60:31-7.

20 Carlson RG, Maytield WR, Normann S, Alexander JA. Radiation-associated valvular disease. Chest 1991:99: 538-45.

21 McEniery PT, Dorosti $K$, Schiavone WA, Pedrick TJ, Sheldon WC Clinical andangiographic features of coronary artery disease after chest irradiation. $A m \mathcal{F}$ Cardiol 1987;60:1020-4.

22 Gustavsson A, Eskilsson J, Landberg T, Svahn-Tapper G, White $T$, Wollmer $P$, et al. Late cardiac effects after manthe field radiotherapy in patients with Hodgkin's disease. Ann Oncol 1990;1:355-63.

23 Kreuser ED, Voller H, Behles C, Schrøder K, Uhrig A, Besserer A, et al. Evaluation of late cardiotoxicity with Besserer A, et al. Evaluation of late cardiotoxicity with
pulsed Doppler echocardiography in patients treated for pulsed Doppler echocardiography in patients treat

24 Orzan F, Brusca A, Conte MR, Presbitero P, Figliomeni MC. Severe coronary artery disease after radiation inical presentation and treatment. Br Heart $\mathcal{f}$ 1993;69:496-500. 